\title{
Optical and Magnetic Properties of Ni Doped ZnS Diluted Magnetic Semiconductors Synthesized by Hydrothermal Method
}

\author{
Meirong Wu, ${ }^{1,2}$ Zhiqiang Wei, $^{1,2}$ Wenhua Zhao, ${ }^{1}$ Xuan Wang, ${ }^{2}$ and Jinlong Jiang ${ }^{2}$ \\ ${ }^{1}$ State Key Laboratory of Advanced Processing and Recycling Nonferrous Metals, Lanzhou University of Technology, \\ Lanzhou 730050, China \\ ${ }^{2}$ School of Science, Lanzhou University of Technology, Lanzhou 730050, China
}

Correspondence should be addressed to Zhiqiang Wei; qianweizuo@163.com

Received 24 March 2017; Revised 16 June 2017; Accepted 12 July 2017; Published 11 September 2017

Academic Editor: Marinella Striccoli

Copyright (C) 2017 Meirong Wu et al. This is an open access article distributed under the Creative Commons Attribution License, which permits unrestricted use, distribution, and reproduction in any medium, provided the original work is properly cited.

\begin{abstract}
Diluted magnetic semiconductors $\mathrm{Zn}_{1-x} \mathrm{Ni}_{x} \mathrm{~S}$ with different consistency ratio $(x=0,0.01,0.03,0.05$, and 0.07$)$ were successfully synthesized by hydrothermal method using ethylenediamine as a modifier. The influence of Ni doping concentration on the microstructure, morphology, and optical and magnetic properties of undoped and Ni doped ZnS nanocrystals was characterized by X-ray diffraction (XRD), high-resolution transmission electron microscopy (HRTEM), X-ray energy dispersive spectrometry (XEDS), ultraviolet-visible spectroscopy (UV-vis), Fourier transform infrared spectroscopy (FT-IR), photoluminescence spectra $(\mathrm{PL})$, and the vibrating sample magnetometer (VSM), respectively. The experiment results show the substitution of $\mathrm{Ni}^{2+}$ on $\mathrm{Zn}^{2+}$ sites without changing the hexagonal wurtzite structure of $\mathrm{ZnS}$ and generate single-phase $\mathrm{Zn}_{1-x} \mathrm{Ni}_{x} \mathrm{~S}$ with good crystallization. The lattice constant causes distortion and decreases with the increase of $\mathrm{Ni}^{2+}$ doped concentration. The appearance of the samples is one-dimensional well-dispersed nanorods. UV-vis spectra reveal the band gap of all $\mathrm{Zn}_{1-x} \mathrm{Ni}_{x} \mathrm{~S}$ samples greater than that of bulk $\mathrm{ZnS}(3.67 \mathrm{eV})$, and blue shift phenomenon occurs. The photoluminescence spectra of undoped and doped samples possess the broad blue emission band in the range of $400-650 \mathrm{~nm}$; the PL intensities of $\mathrm{Zn}_{1-x} \mathrm{Ni}_{x} \mathrm{~S}$ nanorods increase with the increase of $\mathrm{Ni}$ content comparing to pure $\mathrm{ZnS}$ and reach maximum for $x=0.03$. Magnetic measurements indicated that the undoped $\mathrm{ZnS}$ samples are superparamagnetic, whereas the doped samples exhibit ferromagnetism.
\end{abstract}

\section{Introduction}

Diluted magnetic semiconductors refer to a new type of semiconductor material with both spin and charge degrees of freedom that is formed by the substitution of transition metals and rare earth ions to a small fraction of nonmagnetic cations in nonmagnetic semiconductors [1, 2]. DMS nanocrystals have attracted scientific community for new spintronic optoelectronic devices due to its novel properties and broad application prospect, such as fieldemission devices, spin field-effect transistors, spin polarized light emitting diode, optical isolator, and quantum computer [3-8].

$\mathrm{ZnS}$ is one of the prospective candidates for multifunctional semiconductor material device because of its wide band gap $(3.67 \mathrm{eV})$, free exciting binding energy $(60 \mathrm{meV})$, and high index of refraction (2.27) and it possesses good piezoelectric, ferromagnetic, photoelectric, and photosensitive properties. In addition, $\mathrm{ZnS}$ nanocrystals also have high specific surface area and quantum size effect and quantum tunneling effect [9-11], leading to the zinc sulfide doped matrix material exhibiting high quantum efficiency in photoluminescence and electroluminescence, and are often used as an important matrix material multicolor fluorescent powder. Therefore, in order to obtain the intrinsic dilute magnetic semiconductors, transition metal doped $\mathrm{ZnS}$ has been widely studied by different methods. The carrier type, sulfur vacancy, zinc interstitial defect, and crystallization quality of $\mathrm{ZnS}$ can be adjusted by changing the doping elements type and doping amount, controlling the preparation process, so as to effectively control the electrical, magnetic, and optical properties of ZnS [12-16]. Compared with the traditional ways, it can produce many kinds of nanometer powder by hydrothermal method. And its products have high purity, 
small size, uniform distribution, and well chemical activity at low temperature. The solvent interact with the reactants at the molecular level, which provides a better control of stoichiometry, easy control of composition and structure, and ability to tailor particle size and morphology $[17,18]$. At present, the scientific research on the microstructure and optical and magnetic properties of $\mathrm{Ni}$ doped $\mathrm{ZnS}$ is not systematic and comprehensive.

In this paper, we successfully synthesized the $\mathrm{Zn}_{1-x} \mathrm{Ni}_{x} \mathrm{~S}$ diluted magnetic semiconductors with different doping consistency $(x=0,0.01,0.03,0.05$, and 0.07$)$ by hydrothermal method. Using the testing method of HRTEM, XRD, XEDS, UV-vis, FT-IR, PL, and VSM, the sample's properties and microstructure were identified, including structure, morphology, constituent elements, and optical and magnetic properties.

\section{Experimental}

$\mathrm{Zn}_{1-x} \mathrm{Ni}_{x} \mathrm{~S}(x=0,0.01,0.03,0.05$, and 0.07$)$ nanocrystals were prepared using hydrothermal method. All chemical products used in this study are analytical grade and used without further purification. The manufacturing process is as follows: according to the chemical formula $\mathrm{Zn}_{1-x} \mathrm{Ni}_{x} \mathrm{~S}$ and the mole ratio of the metal cation, weighed stoichiometric $\mathrm{Zn}(\mathrm{Ac})_{2} \cdot 2 \mathrm{H}_{2} \mathrm{O},\left(\mathrm{NH}_{2}\right)_{2} \mathrm{CS}$, and $\mathrm{Ni}(\mathrm{Cl})_{2} \cdot 6 \mathrm{H}_{2} \mathrm{O}$ were dissolved in $80 \mathrm{ml}$ ethylenediamine $\left(\mathrm{C}_{2} \mathrm{H}_{8} \mathrm{~N}_{2}\right)$ and deionized water (1:1 in volume ratio) to obtain a solution; the solution was stirred until completely dissolved by magnetic stirrer at room temperature for 1 hour. And then the resulting mixed solution was transferred into a $100 \mathrm{ml}$ Teflon-lined stainless steel autoclave (with the filling ratio of $80 \%$ ), sealed, and maintained at $200^{\circ} \mathrm{C}$ for $12 \mathrm{~h}$ in an oven. After the end of the reaction, the autoclave was taken out and cooled down to room temperature naturally. Finally, the resulting precipitate was repeated alternately washed with deionized water and absolute alcohol several times by centrifugation to remove impurities. The obtained products were dried in oven at $60^{\circ} \mathrm{C}$ for $10 \mathrm{~h}$. Thus, $\mathrm{Zn}_{1-x} \mathrm{Ni}_{x} \mathrm{~S}$ nanocrystals were collected and used for further studies.

The phase and crystalline structures of $\mathrm{Zn}_{1-x} \mathrm{Ni}_{x} \mathrm{~S}$ nanorods were investigated by a Japan Rigaku D/Max-2400 powder X-ray diffractometer with $\mathrm{Cu}-\mathrm{Ka}(\lambda=1.54056 \AA)$ radiation. The size and morphology of the samples were observed using high-resolution transmission electron microscopy (HRTEM, JEM-2010) coupled with an X-ray energy dispersive spectroscopy (XEDS) accessory to the chemical composition of the products. The absorption spectra of samples were recorded using ultraviolet-visible (UV-VIS, TU1901) spectrophotometer. Fourier transform infrared spectroscopy (FT-IR) studies were carried out on Nexus 670 FT-IR spectrometer. Photoluminescence (PL) spectra measurements were performed on a PerkinElmer fluorescence spectrometer by using He-Cd laser as the excitation source with the excitation wavelength of $325 \mathrm{~nm}$. Magnetic hysteresis loops were made at room temperature using a vibrating sample magnetometer (VSM, Lakeshore 7304) with the maximum field of $8 \mathrm{kOe}$.

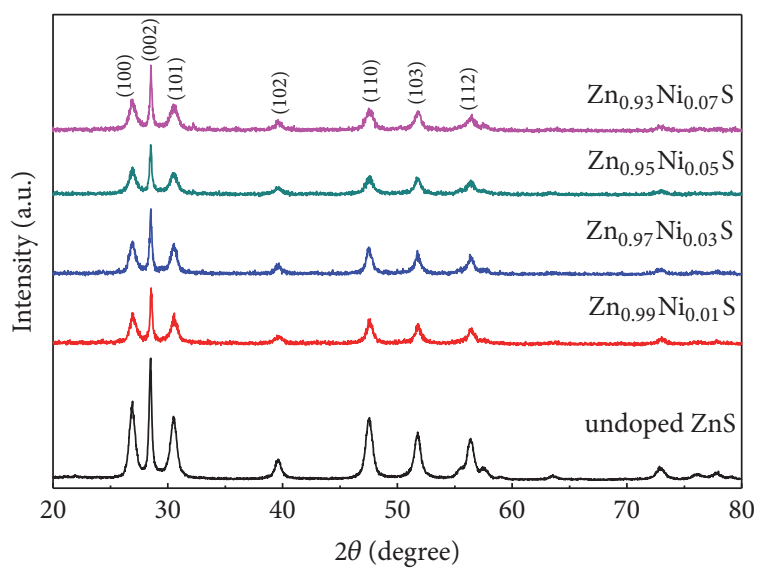

FIGURE 1: XRD patterns of $\mathrm{Zn}_{1-x} \mathrm{Ni}_{x} \mathrm{~S}(x=0,0.01,0.03,0.05$, and $0.07)$ nanorods.

\section{Results and Discussion}

3.1. Structural Analysis. To examine the crystalline structures and phase of the synthesized $\mathrm{Zn}_{1-x} \mathrm{Ni}_{x} \mathrm{~S}(x=0,0.01,0.03$, 0.05 , and 0.07 ) samples with different doping concentration ratio, XRD studies were carried out and the results are shown in Figure 1. It can be clearly observed from the pattern that the diffraction peaks located at $2 \theta=26.91^{\circ}, 28.50^{\circ}, 30.53^{\circ}, 39.61^{\circ}$, $47.56^{\circ}, 51.78^{\circ}$, and $56.39^{\circ}$ corresponding to (100), (002), (101), (102), (110), (103), and (112) crystallographic planes of ZnS, respectively. All diffraction peaks can be well indexed as the hexagonal wurtzite phase $\mathrm{ZnS}$ crystalline structure, which are consistent with the standard spectrum (JCPDS number 361450). No diffraction peak of Ni and other impurity phases can be found in XRD diagram, confirming that there are no secondary phases such as metal clusters or metal oxides in the sample, indicating the formation of the pure single wurtzite phase $\mathrm{ZnS}$ when the doping atomic percentage ranges from $0 \%$ to $7 \%$. Compared with the pure $\mathrm{ZnS}$ sample, the XRD intensity of the doped samples decreases, which may be attributed to declining the crystallization with $\mathrm{Ni}$ ion doping. Thus, it indicates that the change of molar ratio of doped elements does not cause the change of crystal structure of $\mathrm{ZnS} ; \mathrm{Ni}^{2+}$ is effectively introduced into the $\mathrm{ZnS}$ crystal lattice and substitutes for the $\mathrm{Zn}^{2+}$ site.

Based on the XRD results, the average crystalline size of $\mathrm{Zn}_{1-x} \mathrm{Ni}_{x} \mathrm{~S}$ samples can be estimated by using Scherrer formula:

$$
D=\frac{K \lambda}{B \cos \theta},
$$

where $D$ represents the average diameter, $K=0.89$ is the Scherrer constant, $\lambda=1.54056 \AA$ is X-ray wavelength of $\mathrm{Cu}$ Ka radiation, $\theta$ is the diffraction angle for the (002) planes, and $B$ is full width half maximum (FWHM) of (002) diffraction peak in radian. It is noticed that the (002) diffraction peak is much stronger and narrower than the other peaks and the (002) have a rapid growth as compared to (100) and (001), which demonstrates a preferential growth direction along the $c$-axis of the hexagonal crystal. In addition, the (002) 
TABLE 1: Parameters of the XRD patterns for $\mathrm{Zn}_{1-x} \mathrm{Ni}_{x} \mathrm{~S}(x=0,0.01,0.03,0.05$, and 0.07$)$ nanorods.

\begin{tabular}{lcccc}
\hline Ni concentration & $2 \theta\left(^{\circ}\right)$ & $d_{h k l}(\AA)$ & FWHM $\left(^{\circ}\right)$ & Lattice constants $(\AA)$ \\
\hline $0 \%$ & 28.40 & 3.139 & 0.227 & $a=3.829, c=6.279$ \\
$1 \%$ & 28.49 & 3.130 & 0.258 & $a=3.824, c=6.261$ \\
$3 \%$ & 28.52 & 3.128 & 0.260 & $a=3.815, c=6.255$ \\
$5 \%$ & 28.62 & 0.117 & 0.263 & $a=3.805, c=6.230$ \\
$7 \%$ & 28.84 & 3.093 & $a=3.777, c=6.190$ \\
\hline
\end{tabular}

diffraction peak FWHM of Ni doped $\mathrm{ZnS}$ is greater than that of undoped samples, which further confirms $\mathrm{Ni}$ is entering the $\mathrm{ZnS}$ lattice and substitutionally replacing $\mathrm{Zn}$ ions in the lattice of the host material.

The corresponding parameters of $\mathrm{Zn}_{1-x} \mathrm{Ni}_{x} \mathrm{~S}$ samples calculated along (002) plane are shown in Table 1 . The microstructure data of $\mathrm{ZnS}$ nanocrystals were estimated according to the Bragg formula:

$$
2 d_{h k l} \sin \theta=\lambda
$$

where $d_{\mathrm{hkl}}$ denotes the interplanar spacing corresponding to (hkl) crystalline plane and $\theta$ is Bragg's diffraction angle. The lattice parameters $a$ and $c$ can be calculated with the help of crystallographic formula:

$$
a=d_{h k l} \sqrt{\frac{4}{3}\left(h^{2}+h k+l^{2}\right)+\left(\frac{a}{c}\right)^{2} l^{2}} .
$$

The calculation results are given in Table 1 . From Table 1, it can be found that the diffraction peaks position of (002) crystal plane for $\mathrm{Zn}_{1-x} \mathrm{Ni}_{x} \mathrm{~S}$ samples slightly shifts to higher diffraction angles, while the crystalline plane distance decreases with the increase of $\mathrm{Ni}$ doped content. It can be understood that the decrease of the crystalline plane distance will result in the increase of the diffraction angle. The lattice parameters $a$-axis and $c$-axis of $\mathrm{Ni}$ doped $\mathrm{ZnS}$ samples decrease with the increase of $\mathrm{Ni}^{2+}$ doped content, which can be attributed to the substitution of smaller ionic radii $\mathrm{Ni}^{2+}(0.68 \AA)$ into larger ionic radii $\mathrm{Zn}^{2+}(0.74 \AA)$ in the wurtzite structure and causing lattice distortion. Therefore, the crystalline size and the lattice parameter of the samples can be controlled by adjusting the ratio of the doped $\mathrm{Ni}$, and the microstructure of the sample is changed.

3.2. Morphological Studies. In order to explore the surface morphology and microstructure of the obtained samples, the HRTEM observations of undoped and $\mathrm{Ni}$ doped $\mathrm{ZnS}$ samples were carried out. Figure 2 shows that all the samples are comprised of one-dimensional well dispersed rod-like structure with clear edge, smooth surface, and good length to diameter ratio. Figure 2(a) shows the typical HRTEM image of undoped $\mathrm{ZnS}$ sample, which possesses relatively uniform one-dimensional rod-like shape with average diameter around $10 \mathrm{~nm}$, and the length of nanorods ranges from 100 to $150 \mathrm{~nm}$. Compared with the pure $\mathrm{ZnS}$ nanorods, the $\mathrm{Zn}_{0.97} \mathrm{Ni}_{0.03} \mathrm{~S}$ nanorods have slight change in diameter and length shown in Figure 2(b), the diameter of Ni doped $\mathrm{ZnS}$ sample is about $15 \mathrm{~nm}$, and the length ranges from 50 to $100 \mathrm{~nm}$. From the above observations, it can be noticed that the morphology of $\mathrm{Zn}_{0.97} \mathrm{Ni}_{0.03} \mathrm{~S}$ nanorods becomes shorter and coarser and the rod length diameter ratio becomes lower as compared to the undoped $\mathrm{ZnS}$ samples.

Figure 2(c) displays the local high magnification HRTEM micrographs of $\mathrm{Zn}_{0.97} \mathrm{Ni}_{0.03} \mathrm{~S}$ nanorods. It can be seen that the $\mathrm{Zn}_{0.97} \mathrm{Ni}_{0.03} \mathrm{~S}$ nanorods reveal the clear lattice fringe and no obvious defects and exhibit a well oriented growth along the (002) direction with good crystallization, The fringe spacing is about $0.311 \mathrm{~nm}$, which is close to the interplanar distance of the (002) lattice planes of the standard wurtzite-type ZnS structure $(2 \theta=28.500, d=0.313 \mathrm{~nm})$. However, the value of $d$ spacing is smaller than bulk $\mathrm{ZnS}$, which is due to the substitution of smaller ionic radii $\mathrm{Ni}^{2+}(0.68 \AA)$ into larger ionic radii $\mathrm{Zn}^{2+}(0.74 \AA)$. The TEM results are coincided with the conclusion obtained from XRD analysis, which further proved the substitution of $\mathrm{Zn}$ ions by $\mathrm{Ni}$ ions in the $\mathrm{ZnS}$ matrix. The corresponding selected area electron diffraction (SAED) patterns of $\mathrm{Zn}_{0.97} \mathrm{Ni}_{0.03} \mathrm{~S}$ nanorods are shown in Figure $2(\mathrm{~d})$. It can found that the SAED pattern consists of many regular concentric rings with different radius, which indicate that the samples belong to polycrystalline structure. The diffraction ring from inside to outside is corresponding to (100), (002), (101), (102), (110), (103), and (112) planes of $\mathrm{Zn}_{0.97} \mathrm{Ni}_{0.03} \mathrm{~S}$ nanorods, respectively. The SAED pattern further confirms that the obtained samples belong to wurtzite structure and agreement with the result of XRD, indicating that the entry of $\mathrm{Ni}^{2+}$ ions does not degrade the crystallinity of samples.

3.3. Chemical Component Analysis. In order to determine the composition of the samples, the energy dispersive $\mathrm{X}$ ray energy dispersive spectrometry (XEDS) of $\mathrm{Zn}_{1-x} \mathrm{Ni}_{x} \mathrm{~S}$ nanorods was performed. Figure 3 shows the XEDS patterns of the pure $\mathrm{ZnS}$ and $\mathrm{Zn}_{0.97} \mathrm{Ni}_{0.03} \mathrm{~S}$ nanorods. The XEDS spectra of the pure sample are present in Figure 3(a); in addition to the existence of the characteristic peaks of $\mathrm{Zn}$ and $\mathrm{S}$ element, it contains $\mathrm{C}, \mathrm{O}$, and $\mathrm{Cu}$ element. The $\mathrm{C}$ and $\mathrm{O}$ elements may be introduced in the process of washing the samples, which cannot be completely washed with distilled water and absolute alcohol. The $\mathrm{Cu}$ peaks are attributed to the micro grid of the bearing samples during the testing process. The XEDS spectra analysis of $\mathrm{Zn}_{0.97} \mathrm{Ni}_{0.03} \mathrm{~S}$ nanorods in Figure 3(b) confirms the presence of Ni elements in samples. The quantitative atomic and weight percentage of the compositional elements are given in the inset of Figure 3. 


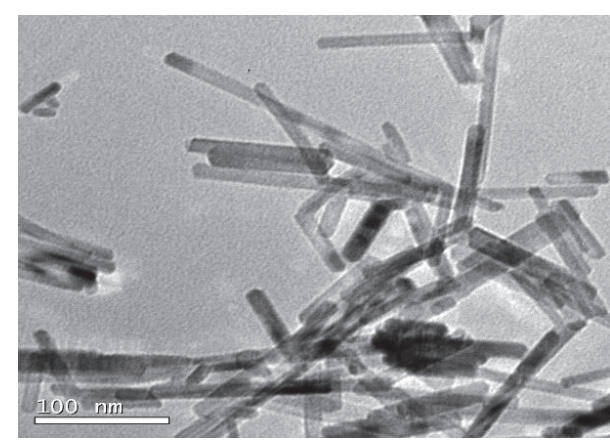

(a)

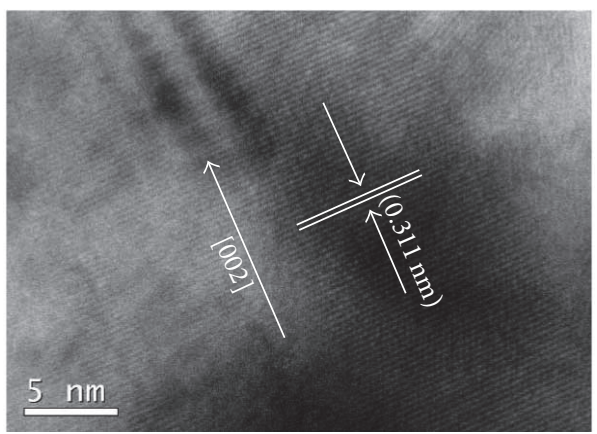

(c)

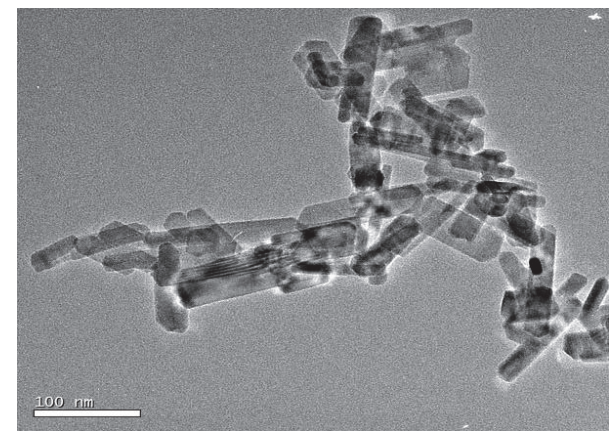

(b)

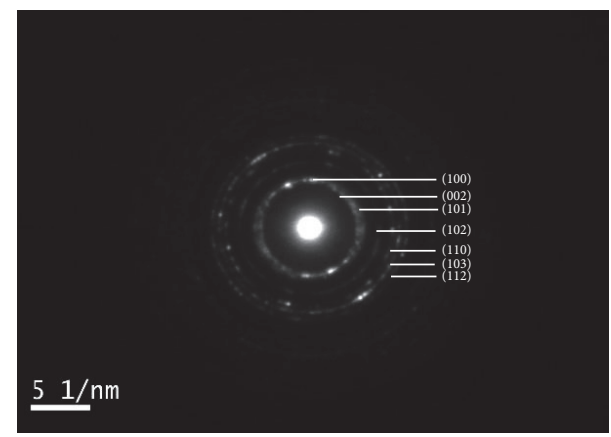

(d)

FIGURE 2: HRTEM images (a-c) and SAED (d) pattern of $\mathrm{ZnS}$ and $\mathrm{Zn}_{0.97} \mathrm{Ni}_{0.03}$ S nanorods.

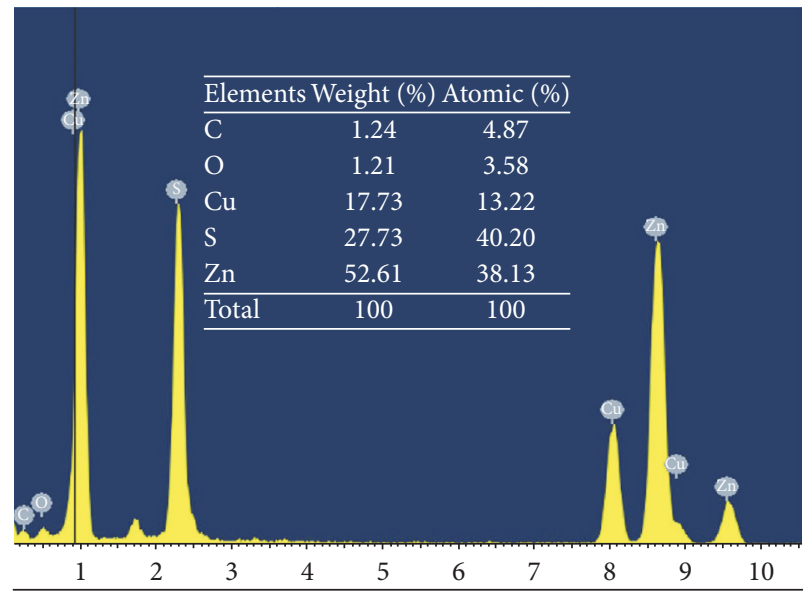

(a)

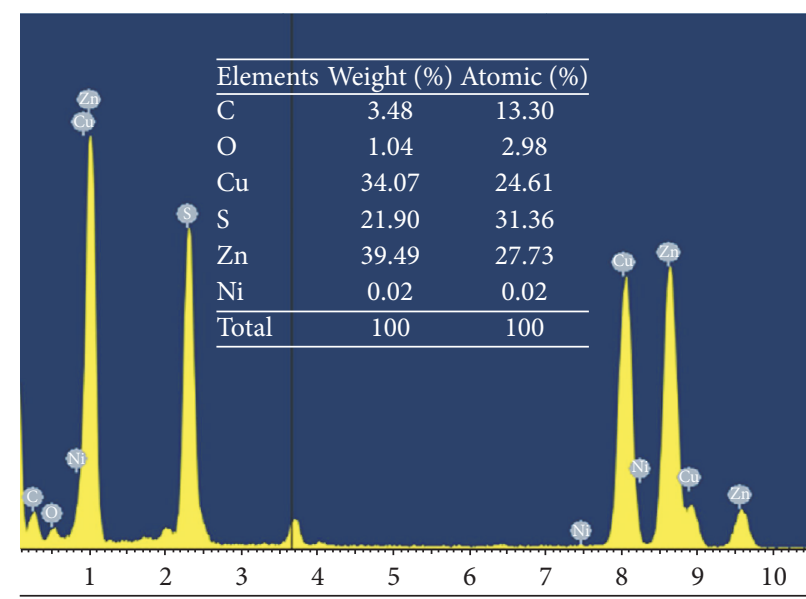

(b)

FIGURE 3: XEDS patterns of pure $\mathrm{ZnS}$ and $\mathrm{Zn}_{0.97} \mathrm{Ni}_{0.03} \mathrm{~S}$ nanorods.

It can be found the calculated weight and atomic percentage are close to the nominal stoichiometry within the experimental error. The XEDS results further verify XRD conclusion, which indicates that $\mathrm{Ni}$ is entering the $\mathrm{ZnS}$ diluted magnetic semiconductor and replacing $\mathrm{Zn}$ ions in $\mathrm{ZnS}$ matrix.

3.4. FT-IR Analysis. In order to investigate the effect of $\mathrm{Ni}$ doping on the optical characteristics of $\mathrm{Zn}_{1-x} \mathrm{Ni}_{x} \mathrm{~S}$ samples, the optical absorption spectra were analyzed using FT-IR spectrometer. Figure 4 shows the FT-IR analysis of $\mathrm{Zn}_{1-x} \mathrm{Ni}_{x} \mathrm{~S}$ $(x=0,0.01,0.03,0.05$, and 0.07$)$ samples in the range of $500-4000 \mathrm{~cm}^{-1}$. For all the samples, the broad peak centered at about $3433 \mathrm{~cm}^{-1}$ can be assigned to the longitudinal stretching vibration mode of chemically bonded hydroxyl groups, resulting from small quantity of adsorbed $\mathrm{H}_{2} \mathrm{O}$ on the sample. The weak bands at 2941 and $2857 \mathrm{~cm}^{-1}$ are attributed to the N-H stretching vibration of ethylenediamine. The band at $1635 \mathrm{~cm}^{-1}$ corresponds to the deformation vibration of water molecule. The band at 1005 to $1280 \mathrm{~cm}^{-1}$ weak vibration modes may be assigned to the organic compounds, which 


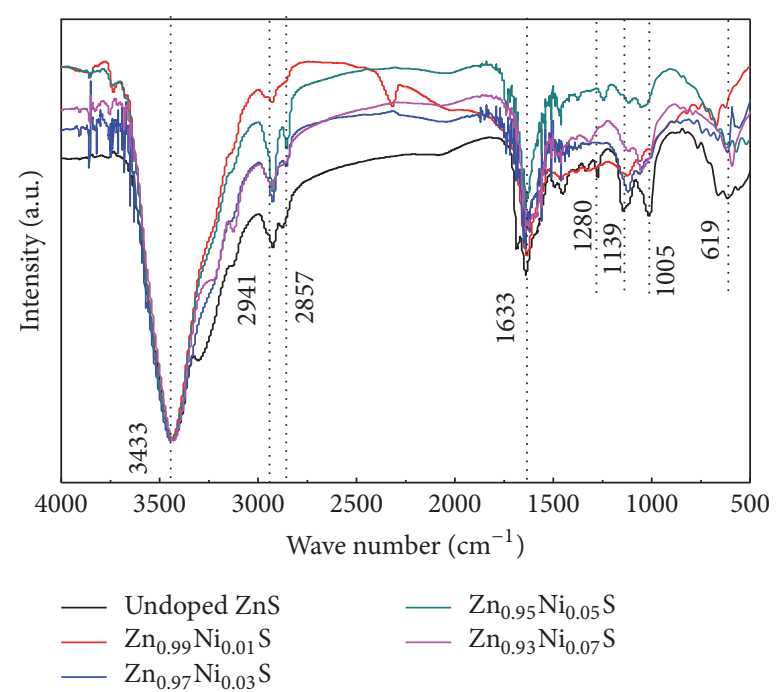

FIGURE 4: FT-IR spectra of $\mathrm{Zn}_{1-x} \mathrm{Ni}_{x} \mathrm{~S}(x=0,0.01,0.03,0.05$, and $0.07)$ nanorods.

may come from the ethylenediamine or alcohol used in the process of preparation [19]. In addition, the wurtzite structure can be identified by the peak at $669 \mathrm{~cm}^{-1}$, assigned to a $\mathrm{Zn}-\mathrm{S}$ bond. With the increasing $\mathrm{Ni}^{2+}$ concentration, the FT-IR spectra of all the samples were not changed obviously, which proved that $\mathrm{Ni}^{2+}$ successfully substituted for the lattice site of $\mathrm{Zn}^{2+}$ and into the $\mathrm{ZnS}$ host lattice without altering the crystal structure. This result is in good agreement with the XRD result.

3.5. UV-Visible Studies. The UV-vis optical absorption spectra for $\mathrm{Zn}_{1-x} \mathrm{Ni}_{x} \mathrm{~S}(x=0,0.01,0.03,0.05$, and 0.07$)$ samples were recorded at room temperature in the wavelength range of $250-700 \mathrm{~nm}$; as shown in Figure 5, it is clear that all $\mathrm{Zn}_{1-x} \mathrm{Ni}_{x} \mathrm{~S}$ samples exhibit strong absorption edges band at UV region in the range of $260-300 \mathrm{~nm}$ and poor absorption at visible region. The gradual doping substitution of $\mathrm{Ni}^{2+}$ in $\mathrm{ZnS}$ lattice results in the difference of absorption coefficient of sample and also has some influence on the position of absorption peak.

Based on the UV-vis results, the optical band gap can be calculated according to Tauc relation as follows:

$$
\alpha h v=A\left(h v-E_{g}\right)^{n},
$$

where $A$ is a constant, $h$ is Plank's constant, $h v$ is the incident photon energy, $E_{g}$ is the band gap of samples, and $\alpha$ is the absorption coefficient which can be obtained using the Kubelka-Munk function:

$$
\alpha=F(R)=\frac{(1-R)^{2}}{2 R},
$$

where $R$ is the percentage of reflected light. For $\mathrm{ZnS}$ nanocrystals semiconductor with direct band structure, $n=$ $1 / 2$ and $(\alpha h \nu)^{2}$ gives the best linear fitting curve in the band edge region. The relationship between $(\alpha h v)^{2}$ and $h v$ is shown in Figure 5(b). The values of $E_{g}$ are obtained by extrapolating the straight portion of the curve on $h v$ axis at $\alpha=0$. The measured values of optical band gap energy for $\mathrm{Zn}_{1-x} \mathrm{Ni}_{x} \mathrm{~S}$ $(x=0,0.01,0.03,0.05$, and 0.07) nanorods are 3.79, 3.77, $3.74,3.75$, and $3.76 \mathrm{eV}$, respectively. It was clearly that the direct band gap values of all $\mathrm{Zn}_{1-x} \mathrm{Ni}_{x} \mathrm{~S}$ samples are greater than that of bulk $\mathrm{ZnS}(3.67 \mathrm{eV})$, and blue shift phenomenon occurs. The blue shift phenomenon is caused by the quantum size effect changes of the electronic transition; due to the decrease of the nanoparticle size, the energy gap becomes wider, which leads to the optical absorption band shift to the short wave direction. On the other hand, small particle size and large surface tension lead to distortion of lattice, the lattice constants decrease, the distortion inside the particle makes the bond length shorter, and the infrared absorption band shifts to higher wave number; the interface effect caused spectral blue shift of nanomaterials.

Furthermore, the influences of Ni doping concentration on the band gap energy of $\mathrm{Zn}_{1-x} \mathrm{Ni}_{x} \mathrm{~S}$ samples are indicated in the inset of Figure 5(b). It is worth noting that the band gap of Ni doped $\mathrm{ZnS}$ samples is lower than that of undoped sample and the value gradually decreases with the increase of $\mathrm{Ni}$ doped concentration and the band gap up to a minimum $3.74 \mathrm{eV}$ for $3 \% \mathrm{Ni}$, whereas when the Ni doping concentration is greater than $3 \%$, the band gap of $\mathrm{Zn}_{1-x} \mathrm{Ni}_{x} \mathrm{~S}$ samples increases slightly with the increase of Ni concentration. The observed lower band gap (red shift) at low doping concentration may be due to the sp- $\mathrm{d}$ spin exchange interactions. The correction probability of the positive and negative potential to the conduction band and the valence band edge may be enhanced, respectively, under the $s-d$ and $p-d$ exchange interactions, which result in band gap narrowing [20]. But the higher band gap (blue shift) at high doping (from 3\% to $7 \% \mathrm{Ni}$ ) may be explained by the Burstein-Moss shift; when the doping concentration of $\mathrm{Ni}$ ion is rather high, the carrier density donated by $\mathrm{Ni}$ ions will increase [21]. The increase of carrier density shifts the Fermi level close to conduction band and the changes of transition levels lead to the energy gap broadening.

3.6. Photoluminescence Studies. The most effective tool for exploring the defect structure in semiconductor is nondestructive photoluminescence (PL) measurements. It helps to characterize the impurity and defect energy states even when they are presented in very low concentrations whether at surface or interfaces. Figure 6(a) shows the room photoluminescence spectra of $\mathrm{Zn}_{1-x} \mathrm{Ni}_{x} \mathrm{~S}$ samples. It exhibits that all samples possess the broad blue emission band in the range of $400-650 \mathrm{~nm}$, and the broad emission bands may be attributed to the recombination of electron hole induced by the change of local charge distribution at the defect sites [22].

The PL emission intensity of $\mathrm{Zn}_{1-x} \mathrm{Ni}_{x} \mathrm{~S}$ nanorods is indicated in the inset of Figure 6(a). It is noted that the PL intensities of $\mathrm{Zn}_{1-x} \mathrm{Ni}_{x} \mathrm{~S}$ nanorods exhibit dramatic change with the increase of doping amount; the PL emission intensity of the doped samples increases comparing to pure $\mathrm{ZnS}$. When $\mathrm{Ni}$ doping concentration $x=0.03$, the intensity of the PL spectrum reaches maximum, whereas when the Ni doping concentration is greater than $3 \%$, the intensity of $\mathrm{Zn}_{1-x} \mathrm{Ni}_{x} \mathrm{~S}$ 


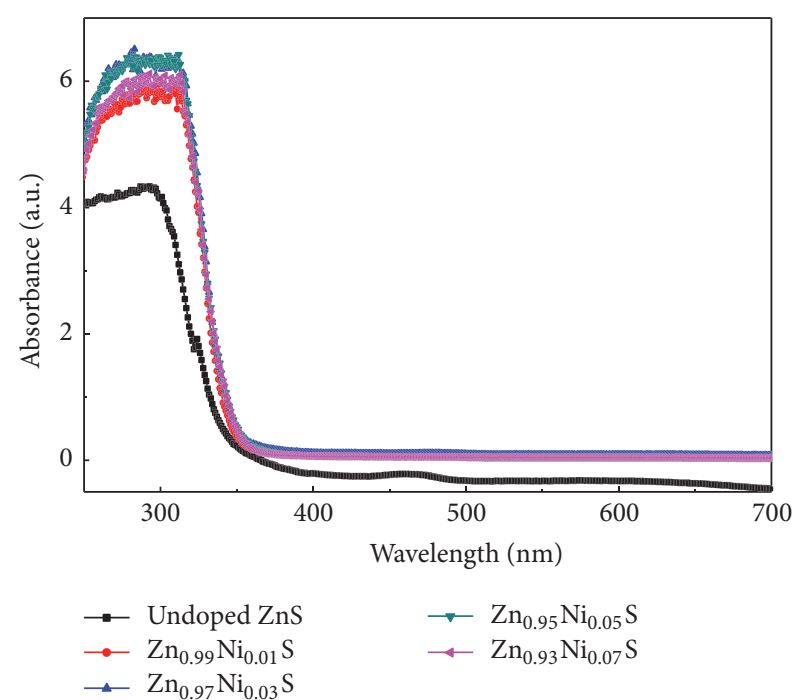

(a)

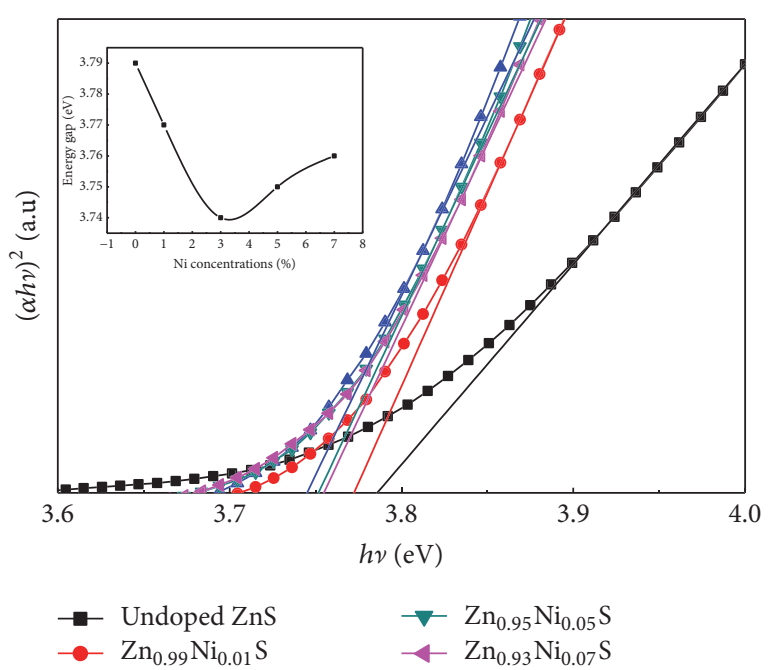

(b)

FIGURE 5: UV-vis absorption spectra (a) and Tauc plot of $(\alpha h v)^{2}$ versus $h v(\mathrm{~b})$ of $\mathrm{Zn}_{1-x} \mathrm{Ni}_{x} \mathrm{~S}(x=0,0.01,0.03,0.05$, and 0.07$)$ nanorods.
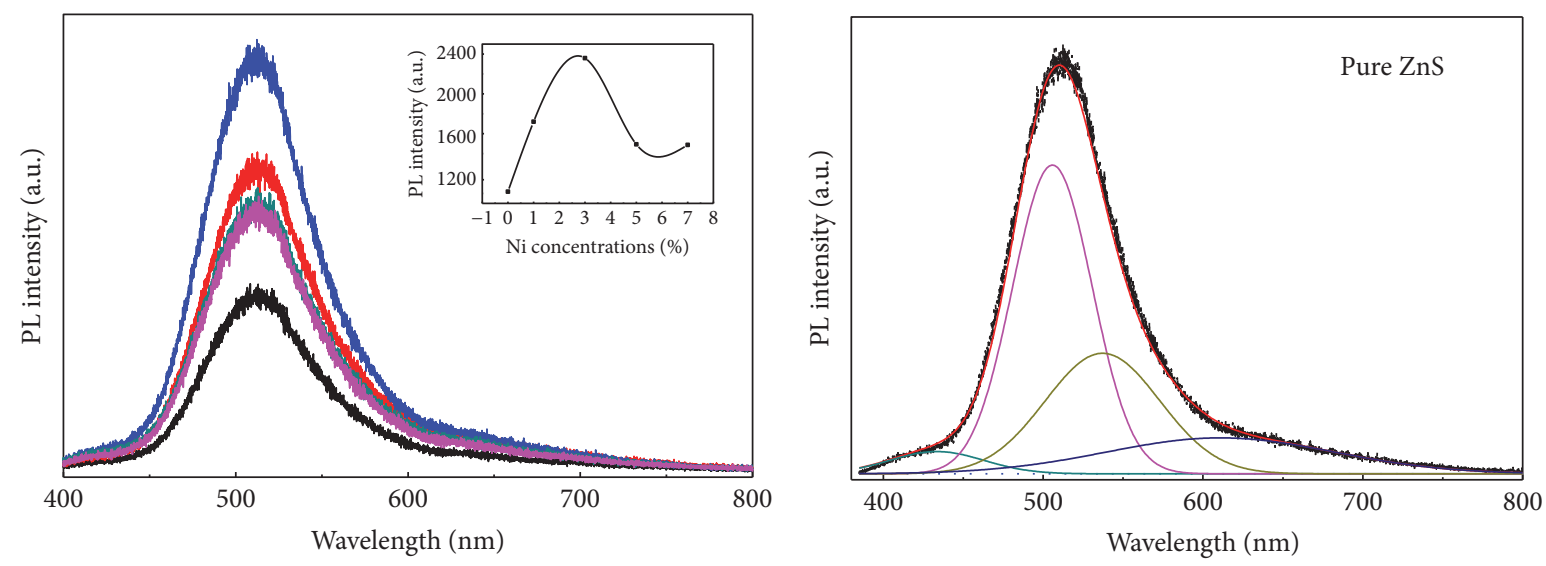

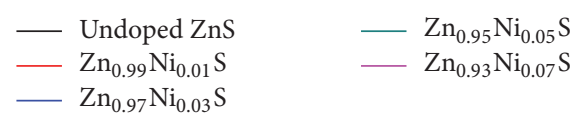

(a)

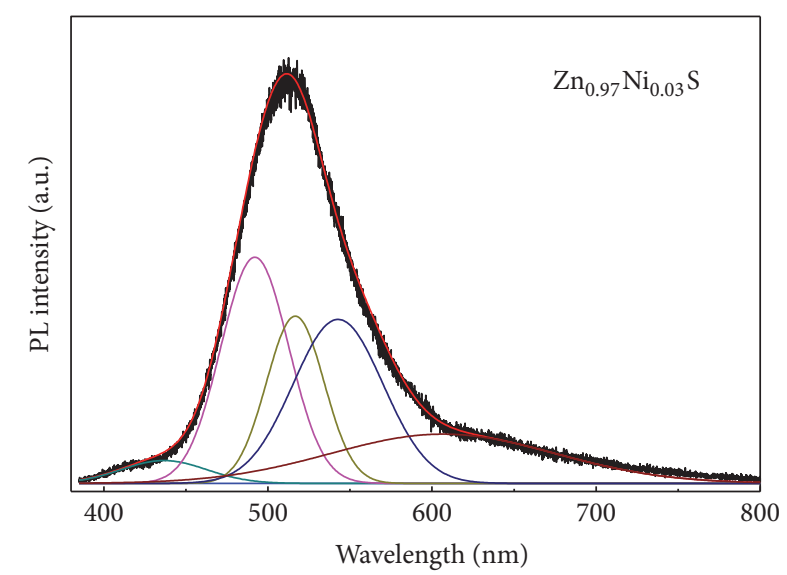

(c) (b)

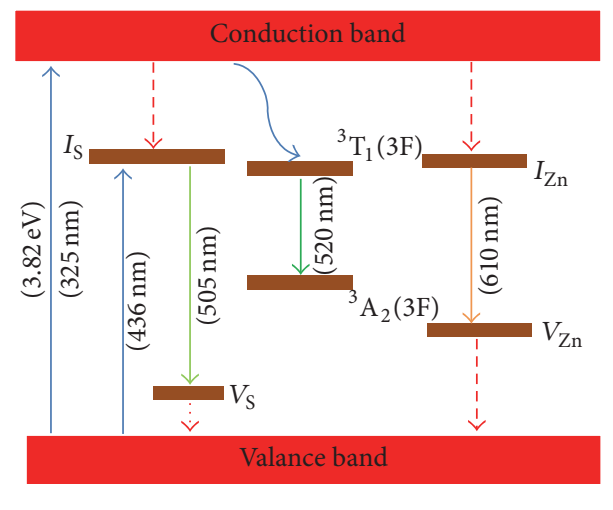

(d)

Figure 6: (a) Emission spectra of $\mathrm{Zn}_{1-x} \mathrm{Ni}_{x} \mathrm{~S}$ nanorods. Gaussian fit of PL data for (b) $x=0$ and (c) $x=0.03$. (d) Schematic energy level diagram for the $\mathrm{Zn}_{1-x} \mathrm{Ni}_{x} \mathrm{~S}$ nanorods. 


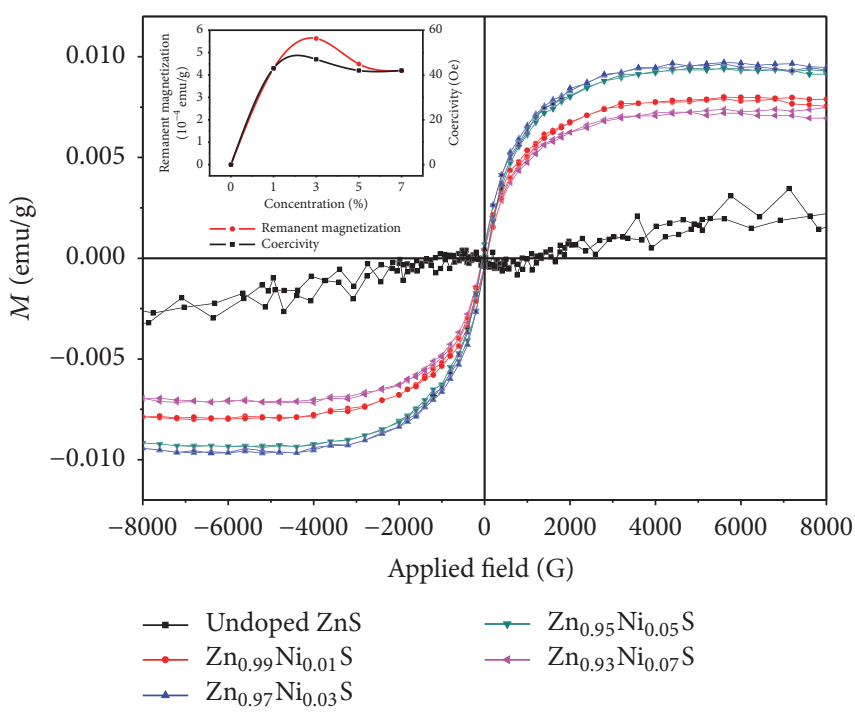

(a)

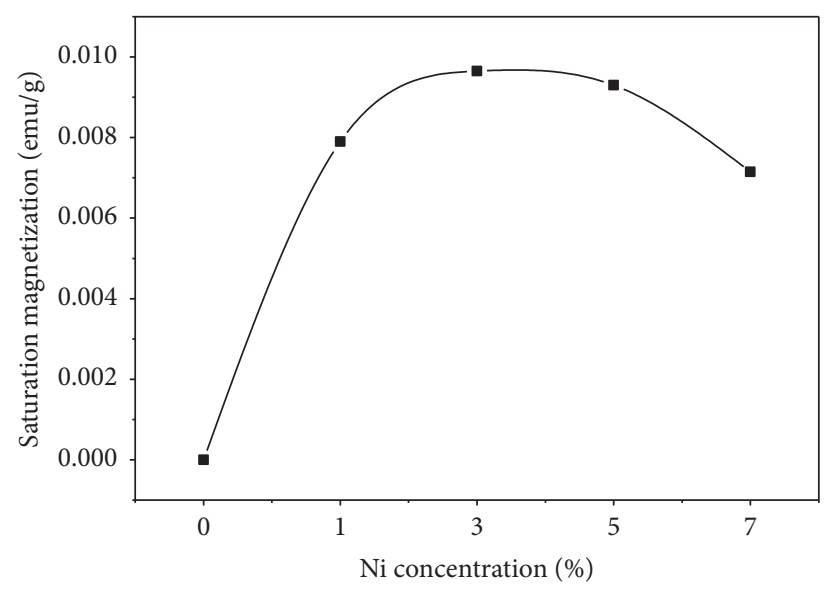

(b)

Figure 7: (a) Room temperature M-H plots of $\mathrm{Zn}_{1-x} \mathrm{Ni}_{x} \mathrm{~S}$ nanorods; (b) the variation of saturation magnetization with Ni doping concentration.

samples decreases slightly with the increase of $\mathrm{Ni}$ amount. The substitution of $\mathrm{Zn}^{2+}$ ions by $\mathrm{Ni}^{2+}$ ions could increase the number of trapped electron hole pairs and emit more photons and generate new radiation centers, which enhances the PL intensity [23]. The subsequent quenching may be attributed to the capture ability of transition metal nickel ions better than the anion vacancy defect centers to the photo-excited electrons. It has been reported that the doped transition metals act as electron trapping centers at higher doping concentration, which result in nonradiative recombination processes increase [24]. As a result, the continuous increase of $\mathrm{Ni}$ ion doping concentration will cause the quenching of $\mathrm{PL}$ emission intensity.

Pure ZnS samples show an asymmetric strong green emission peak at $510 \mathrm{~nm}$, which can be decomposed into four Gaussian peaks, respectively, centered at $424 \mathrm{~nm}, 505 \mathrm{~nm}$, $549 \mathrm{~nm}$, and $628 \mathrm{~nm}$ as shown in Figure 6(b). According to the energy diagram of the defects distributed in the $\mathrm{ZnS}$, generally speaking, the mechanism of PL emission in $\mathrm{ZnS}$ nanostructures is composed of two parts: the zinc vacancy $\left(V_{\mathrm{Zn}}\right)$ and the interstitial sulfur $\left(I_{\mathrm{S}}\right)$ atom as acceptor state and the sulfur vacancy $\left(V_{\mathrm{S}}\right)$ and interstitial $\operatorname{zinc}\left(I_{\mathrm{Zn}}\right)$ atoms as the local donor state. Interstitial sulfur states should be located closer to the valence band edge than interstitial zinc states to the conduction band edge while sulfur vacancies should be located closer to the conduction band edge than zinc vacancies to the valence band edge. Moreover, energy levels of vacancies are deeper than interstitial states [25]. The violet emission band at $424 \mathrm{~nm}$ is a sulfur vacancy $\left(V_{\mathrm{S}}\right)$ assisted one, caused by the transition from the sulfur vacancy state to the valence band edge state of $\mathrm{ZnS}$ nanorods [26]. The emission band centered at $505 \mathrm{~nm}$ is attributed to the transfer of trapped electrons on sulfur vacancies to interstitial sulfur states producing the green luminescence. The emission band at $549 \mathrm{~nm}$ may be due to sulfur species on the surface of $\mathrm{ZnS}$
NWs [27]. The orange emission peak at $628 \mathrm{~nm}$ is assigned to the recombination between the interstitial zinc states and the zinc vacancies [28]. Figure 6(c) shows the Gaussian fitting of PL data of $\mathrm{Zn}_{0.97} \mathrm{Ni}_{0.03} \mathrm{~S}$ nanorods; this spectrum consists of five emission bands centered at $436 \mathrm{~nm}, 492 \mathrm{~nm}$, $520 \mathrm{~nm}, 543 \mathrm{~nm}$, and $606 \mathrm{~nm}$. In comparison with pure ZnS, an additional emission centered at around $520 \mathrm{~nm}$ is observed besides the emissions from pure $\mathrm{ZnS}$. This emission is closely related to the ${ }^{3} \mathrm{~T}_{1}-{ }^{3} \mathrm{~A}_{2}$ transition within the $3 \mathrm{~F}$ shell of $\mathrm{Ni}^{2+}$ ions; the lowest multiplet term $3 \mathrm{~F}$ of the free $\mathrm{Ni}^{2+}$ ion is split into ${ }^{3} \mathrm{~T}_{1},{ }^{3} \mathrm{~T}_{2}$, and ${ }^{3} \mathrm{~A}_{2}$ by the anisotropic hybridization, resulting in the $\mathrm{d}$-d photon transition in $\mathrm{Ni}^{2+}$ and forming the $\mathrm{Ni}^{2+}$ luminescence center in the $\mathrm{ZnS}$ [29]. And normally the observed green emission is related to the ${ }^{3} \mathrm{~T}_{1-}{ }^{3} \mathrm{~A}_{2}$ transition of $\mathrm{Ni}^{2+}$ ions. Thus, the emission centered at $520 \mathrm{~nm}$ in Figure 6(c) further validates that the $\mathrm{Ni}^{2+}$ ions successfully entered the $\mathrm{ZnS}$ host. Based on the above PL analysis, the schematic energy level mechanism of all these observed transitions above PL analysis in Ni doped $\mathrm{ZnS}$ nanostructures is shown in Figure 6(d).

3.7. Magnetic Properties. The magnetic behavior of Ni doped $\mathrm{ZnS}$ samples with different doping concentrations was measured at room temperatures by VSM using a magnetic field $(\mathrm{H})$ of $8 \mathrm{kOe}$. The $\mathrm{M}-\mathrm{H}$ curves of $\mathrm{Zn}_{1-x} \mathrm{Ni}_{x} \mathrm{~S}(x=0,0.01$, $0.03,0.05$, and 0.07 ) samples measured at room temperature are given in Figure 7(a). It shows that pure $\mathrm{ZnS}$ has paramagnetic behavior with few values of coercivity and remnant magnetization; whereas all Ni doped ZnS samples exhibited obvious ferromagnetic features at room temperature, the paramagnetic behavior of pure $\mathrm{ZnS}$ nanorods is ascribed to surface defects and is in corroboration with PL studies. Eryong et al. [30] have also observed such paramagnetic behavior in Fe-doped $\mathrm{ZnS}$ nanoparticles. The variation of coercivity 
(Hc) and remanent magnetization (Ms) with $\mathrm{Ni}$ concentration of $\mathrm{Zn}_{1-x} \mathrm{Ni}_{x} \mathrm{~S}$ nanorods are indicated in the inset of Figure 7(a). Compared with paramagnetic behavior of pure $\mathrm{ZnS}$, the origin of the observed ferromagnetic properties of $\mathrm{Ni}$ doped $\mathrm{ZnS}$ samples is mainly due to the substitution of $\mathrm{Ni}^{2+}$ on $\mathrm{Zn}^{2+}$ sites not due to Ni cluster or its metal oxides, proved by the XEDS and XRD studies; no such secondary phases have been observed.

The variation of saturation magnetization with Ni doping concentration of $\mathrm{Zn}_{1-x} \mathrm{Ni}_{x} \mathrm{~S}(x=0,0.01,0.03,0.05$, and 0.07$)$ nanorods is given in Figure $7(\mathrm{~b})$. The saturation magnetization of Ni doped samples is greater than that pure $\mathrm{ZnS}$, which is due to very small size of $\mathrm{Ni}$ doped $\mathrm{ZnS}$ nanorods; surface to volume ratio is expected to be very high which further leads to surface defects [31,32]. As the doping concentration of $\mathrm{Ni}$ ions increases the magnetization value also increases till reaching a maximum at $3 \%$; subsequently, the saturation magnetization decreases with the increase of $\mathrm{Ni}$ concentration. There may be two exchange interactions in the presence of $\mathrm{Zn}_{1-x} \mathrm{Ni}_{x} \mathrm{~S}$ nanorods. On the one hand there is the nearest neighbor antiferromagnetic coupling of $\mathrm{Ni}$ ion pair in doped ZnS nanorods. On the other hand there is is the exchange interaction between the localized " $d$ " spin on $\mathrm{Ni}^{2+}$ and free delocalized carrier, which strongly depends on the hybridization between the $\mathrm{d}$ shell of $\mathrm{Ni}^{2+}$ ions and the $\mathrm{p}$ shell of their near neighbor $\mathrm{S}^{2-}$ ions [33]. When the doping concentration is low, the small magnetic dipoles existing on the surface of the nanorods interact with their nearest neighbors inside the particles, producing exchange energy that forces the other neighboring dipoles to be aligned in the same direction. Due to the high specific surface area of nanorods, the number of magnetic dipoles of the same orientation will be enhanced in the same direction $[34,35]$. At the same time, the ferromagnetic coupling plays a dominant role in the ferromagnetic contribution to the sample. Consequently, the total magnetization increases with the $\mathrm{Ni}$ content till reaching a maximum at 3\%. At higher dopant concentration, the $\mathrm{Ni}$ cation density increases with increased doping concentrations, which lead to the distance between $\mathrm{Ni}-\mathrm{Ni}$ ions being decreased and antiferromagnetic interaction being strengthened. These antiferromagnetic coupling effects between $\mathrm{Ni}$ ions can quench the magnetic moment, resulting in lower total magnetization. The results indicate that for room temperature ferromagnetism enhancement of $\mathrm{ZnS}$ nanorods, the optimum doping level of $\mathrm{Ni}^{2+}$ is about $3 \%$.

\section{Conclusions}

(1) Diluted magnetic semiconductors $\mathrm{Zn}_{1-x} \mathrm{Ni}_{x} \mathrm{~S}$ of the wurtzite structure with different consistency ratio $(x=0$, $0.01,0.03,0.05$, and 0.07 ) were successfully synthesized via a hydrothermal method. All the samples synthesized by this method are one-dimensional rod-like shape with good dispersion; XRD studies exhibit the substitution of $\mathrm{Ni}^{2+}$ on $\mathrm{Zn}^{2+}$ sites without changing the hexagonal structure of $\mathrm{ZnS}$ and generate single-phase $\mathrm{Zn}_{1-x} \mathrm{Ni}_{x} \mathrm{~S}$.

(2) UV-vis spectra reveal the band gap of all $\mathrm{Zn}_{1-x} \mathrm{Ni}_{x} \mathrm{~S}$ samples greater than that of bulk $\mathrm{ZnS}(3.67 \mathrm{eV})$, and blue shift phenomenon occurs. The photoluminescence spectra of doped and undoped samples possess the broad blue emission band in the range of $400-650 \mathrm{~nm}$; the PL intensities of $\mathrm{Zn}_{1-x} \mathrm{Ni}_{x} \mathrm{~S}$ nanorods increase with the increase of Ni doping concentration comparing to pure $\mathrm{ZnS}$ and reach maximum for $x=0.03$.

(3) Magnetic measurements indicate that the undoped ZnS samples are superparamagnetic, whereas the doped samples exhibit ferromagnetism. The saturation magnetization increase weakened significantly with increasing $\mathrm{Ni}$ concentration comparing to pure $\mathrm{ZnS}$ and reaches minimum for $3 \% \mathrm{Ni}$.

\section{Conflicts of Interest}

The authors declare that they have no conflicts of interest.

\section{Acknowledgments}

This work was supported by the National Natural Science Foundation of China (Grant no. 51261015) and the Natural Science Foundation of Gansu Province, China (Grant no. 1308RJZA238).

\section{References}

[1] K. M. Yu, W. Walukiewicz, J. Wu, and etal., "Diluted II-VI oxide semiconductors with multiple band gaps," Physical Review Letters, vol. 91, no. 24, Article ID 246403, pp. 246-403, 2003.

[2] J. Tang and K. L. Wang, "Electrical spin injection and transport in semiconductor nanowires: challenges, progress and perspectives," Nanoscale, vol. 7, no. 10, pp. 4325-4337, 2015.

[3] P. Chuang, S.-C. Ho, L. W. Smith et al., "All-electric allsemiconductor spin field-effect transistors," Nature Nanotechnology, vol. 10, no. 1, pp. 35-39, 2014.

[4] H. Riel, L.-E. Wernersson, M. Hong, and J. A. Del Alamo, "III-V compound semiconductor transistors-From planar to nanowire structures," MRS Bulletin, vol. 39, no. 8, pp. 668-677, 2014.

[5] Y. Wang and N. Herron, "Nanometer-sized semiconductor clusters: materials synthesis, quantum size effects, and photophysical properties," The Journal of Physical Chemistry, vol. 95, no. 2, pp. 525-532, 1991.

[6] G. Miao and J. S. Moodera, "Spin manipulation with magnetic semiconductor barriers," Physical Chemistry Chemical Physics, vol. 17, no. 2, pp. 751-761, 2015.

[7] J. T. Muhonen, J. P. Dehollain, A. Laucht et al., "Storing quantum information for 30 seconds in a nanoelectronic device," Nature Nanotechnology, vol. 9, no. 12, pp. 986-991, 2014.

[8] M. J. Iqbal and S. Iqbal, "Synthesis of stable and highly luminescent beryllium and magnesium doped $\mathrm{ZnS}$ quantum dots suitable for design of photonic and sensor material," Journal of Luminescence, vol. 134, pp. 739-746, 2013.

[9] H. Kumar, P. B. Barman, and R. R. Singh, "Effect of size and shell: enhanced optical and surface properties of CdS, ZnS and CdS/ZnS quantum dots," Physica E: Low-Dimensional Systems and Nanostructures, vol. 67, pp. 168-177, 2015.

[10] Q.-L. Li and S.-N. Ding, "Multicolor electrochemiluminescence of core-shell CdSe@ZnS quantum dots based on the size effect," Science China Chemistry, vol. 59, no. 11, pp. 1508-1512, 2016. 
[11] A. Fairbrother, V. Izquierdo-Roca, X. Fontané et al., "ZnS grain size effects on near-resonant Raman scattering: optical nondestructive grain size estimation," Cryst Eng Comm, vol. 16, no. 20, pp. 4120-4125, 2014.

[12] D. A. Reddy, C. Liu, R. P. Vijayalakshmi, and B. K. Reddy, "Effect of Al doping on the structural, optical and photoluminescence properties of ZnS nanoparticles," Journal of Alloys and Compounds, vol. 582, pp. 257-264, 2014.

[13] A. Roychowdhury, S. P. Pati, S. Kumar, and D. Das, "Effects of magnetite nanoparticles on optical properties of zinc sulfide in fluorescent-magnetic $\mathrm{Fe}_{3} \mathrm{O}_{4} / \mathrm{ZnS}$ nanocomposites," Powder Technology, vol. 254, pp. 583-590, 2014.

[14] D. Saikia, R. Raland, and J. P. Borah, "Influence of Fe doping on the structural, optical and magnetic properties of $\mathrm{ZnS}$ diluted magnetic semiconductor," Physica E: Low-Dimensional Systems and Nanostructures, vol. 83, pp. 56-63, 2016.

[15] J. Cao, D. Han, B. Wang et al., "Low temperature synthesis, photoluminescence, magnetic properties of the transition metal doped wurtzite ZnS nanowires," Journal of Solid State Chemistry, vol. 200, pp. 317-322, 2013.

[16] A. Goktas, F. Aslan, and A. Tumbul, "Nanostructured Cu-doped ZnS polycrystalline thin films produced by a wet chemical route: the influences of $\mathrm{Cu}$ doping and film thickness on the structural, optical and electrical properties," Journal of Sol-Gel Science and Technology, vol. 75, no. 1, pp. 45-53, 2015.

[17] K. Byrappa and T. Adschiri, "Hydrothermal technology for nanotechnology," Progress in Crystal Growth and Characterization of Materials, vol. 53, no. 2, pp. 117-166, 2007.

[18] L. Wang, J. Dai, X. Liu, Z. Zhu, X. Huang, and P. Wu, "Morphology-controlling synthesis of $\mathrm{ZnS}$ through a hydrothermal/solvthermal method," Ceramics International, vol. 38, no. 3, pp. 1873-1878, 2012.

[19] L. Chai, J. Du, S. Xiong, H. Li, Y. Zhu, and Y. Qian, "Synthesis of wurtzite $\mathrm{ZnS}$ nanowire bundles using a solvothermal technique," Journal of Physical Chemistry C, vol. 111, no. 34, pp. 12658-12662, 2007.

[20] K. J. Kim and Y. R. Park, "Optical investigation of $\mathrm{Zn}_{1-x} \mathrm{Fe}_{x} \mathrm{O}$ films grown on $\mathrm{Al}_{2} \mathrm{O}_{3}(0001)$ by radio-frequency sputtering," Journal of Applied Physics, vol. 96, no. 8, pp. 4150-4153, 2004.

[21] M. F. Malek, M. H. Mamat, N. D. Md Sin, and M. Rusop, "Effects of Sn dopant on structural and optical properties of zno thin film prepared by sol-gel route," Applied Mechanics and Materials, vol. 773-774, pp. 617-621, 2015.

[22] S. K. Mehta, S. Kumar, and M. Gradzielski, "Growth, stability, optical and photoluminescent properties of aqueous colloidal ZnS nanoparticles in relation to surfactant molecular structure," Journal of Colloid and Interface Science, vol. 360, no. 2, pp. 497507, 2011.

[23] N. Dixit, N. Anasane, M. Chavda, D. Bodas, and H. P. Soni, "Inducing multiple functionalities in $\mathrm{ZnS}$ nanoparticles by doping $\mathrm{Ni}_{+2}$ ions," Materials Research Bulletin, vol. 48, no. 6, pp. 2259-2267, 2013.

[24] G. Rani and P. D. Sahare, "Spectroscopy of nickel-doped zinc sulfide nanoparticles," Spectroscopy Letters, vol. 46, no. 6, pp. 391-396, 2013.

[25] H. Tang, G. Xu, L. Weng, L. Pan, and L. Wang, "Luminescence and photophysical properties of colloidal ZnS nanoparticles," Acta Materialia, vol. 52, no. 6, pp. 1489-1494, 2004.

[26] V. P. Devarajan, D. Nataraj, T. Pazhanivel et al., "Molecular conformation dependent emission behaviour (blue, red and white light emissions) of all-trans- $\beta$-carotene- $\mathrm{ZnS}$ quantum dot hybrid nanostructures," Journal of Materials Chemistry, vol. 22, no. 35, pp. 18454-18462, 2012.

[27] Z. Li, B. Liu, X. Li et al., "Synthesis of ZnS nanocrystals with controllable structure and morphology and their photoluminescence property," Nanotechnology, vol. 18, no. 25, Article ID 255602, 2007.

[28] X. Wang, J. Shi, Z. Feng, M. Li, and C. Li, "Visible emission characteristics from different defects of ZnS nanocrystals," Physical Chemistry Chemical Physics, vol. 13, no. 10, pp. 47154723, 2011.

[29] P. Yang, M. Lü, D. Xü et al., "Strong green luminescence of $\mathrm{Ni}_{2+}$ doped ZnS nanocrystals," Applied Physics A: Materials Science \& Processing, vol. 74, no. 2, pp. 257-259, 2002.

[30] N. Eryong, L. Donglai, Z. Yunsen et al., "Photoluminescence and magnetic properties of Fe-doped $\mathrm{ZnS}$ nano-particles synthesized by chemical co-precipitation," Applied Surface Science, vol. 257, no. 21, pp. 8762-8766, 2011.

[31] P. Kaur, S. Kumar, C.-L. Chen et al., "Gd doping induced weak ferromagnetic ordering in $\mathrm{ZnS}$ nanoparticles synthesized by low temperature co-precipitation technique," Materials Chemistry and Physics, vol. 186, pp. 124-130, 2017.

[32] P. Kaur, S. Kumar, A. Singh et al., "Investigations on doping induced changes in structural, electronic structure and magnetic behavior of spintronic Cr-ZnS nanoparticles," Superlattices and Microstructures, vol. 83, pp. 785-795, 2015.

[33] P. K. Sharma, R. K. Dutta, and A. C. Pandey, "Effect of nickel doping concentration on structural and magnetic properties of ultrafine diluted magnetic semiconductor $\mathrm{ZnO}$ nanoparticles," Journal of Magnetism and Magnetic Materials, vol. 321, no. 20, pp. 3457-3461, 2009.

[34] S. Kumar, C. L. Chen, C. L. Dong et al., "Room temperature ferromagnetism in $\mathrm{Ni}$ doped $\mathrm{ZnS}$ nanoparticles," Journal of Alloys and Compounds, vol. 554, pp. 357-362, 2013.

[35] P. Kaur, S. Kumar, A. Singh, and S. M. Rao, "Improved magnetism in $\mathrm{Cr}$ doped $\mathrm{ZnS}$ nanoparticles with nitrogen codoping synthesized using chemical co-precipitation technique," Journal of Materials Science: Materials in Electronics, vol. 26, no. 11, pp. 9158-9163, 2015. 

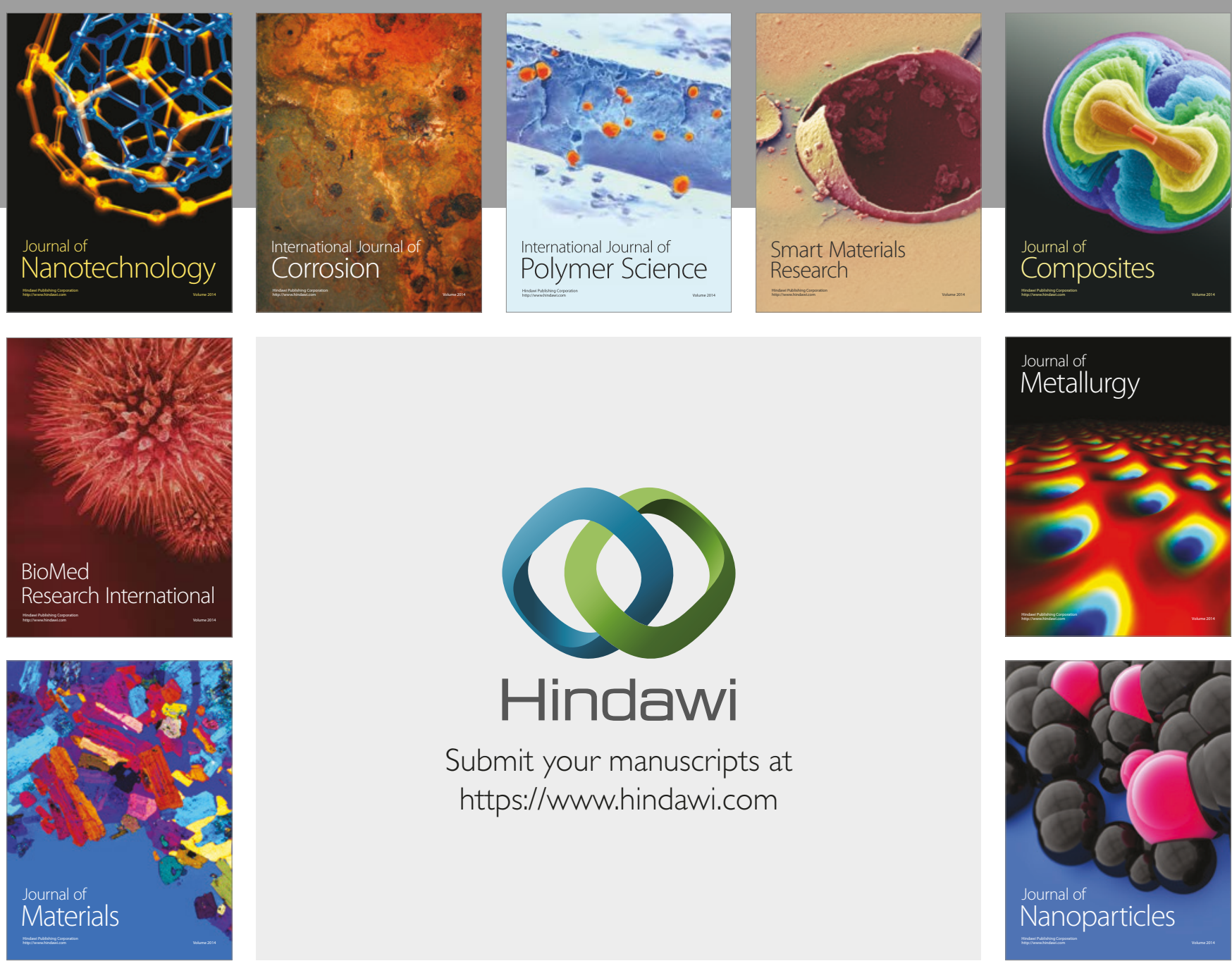

\section{Hindawi}

Submit your manuscripts at

https://www.hindawi.com
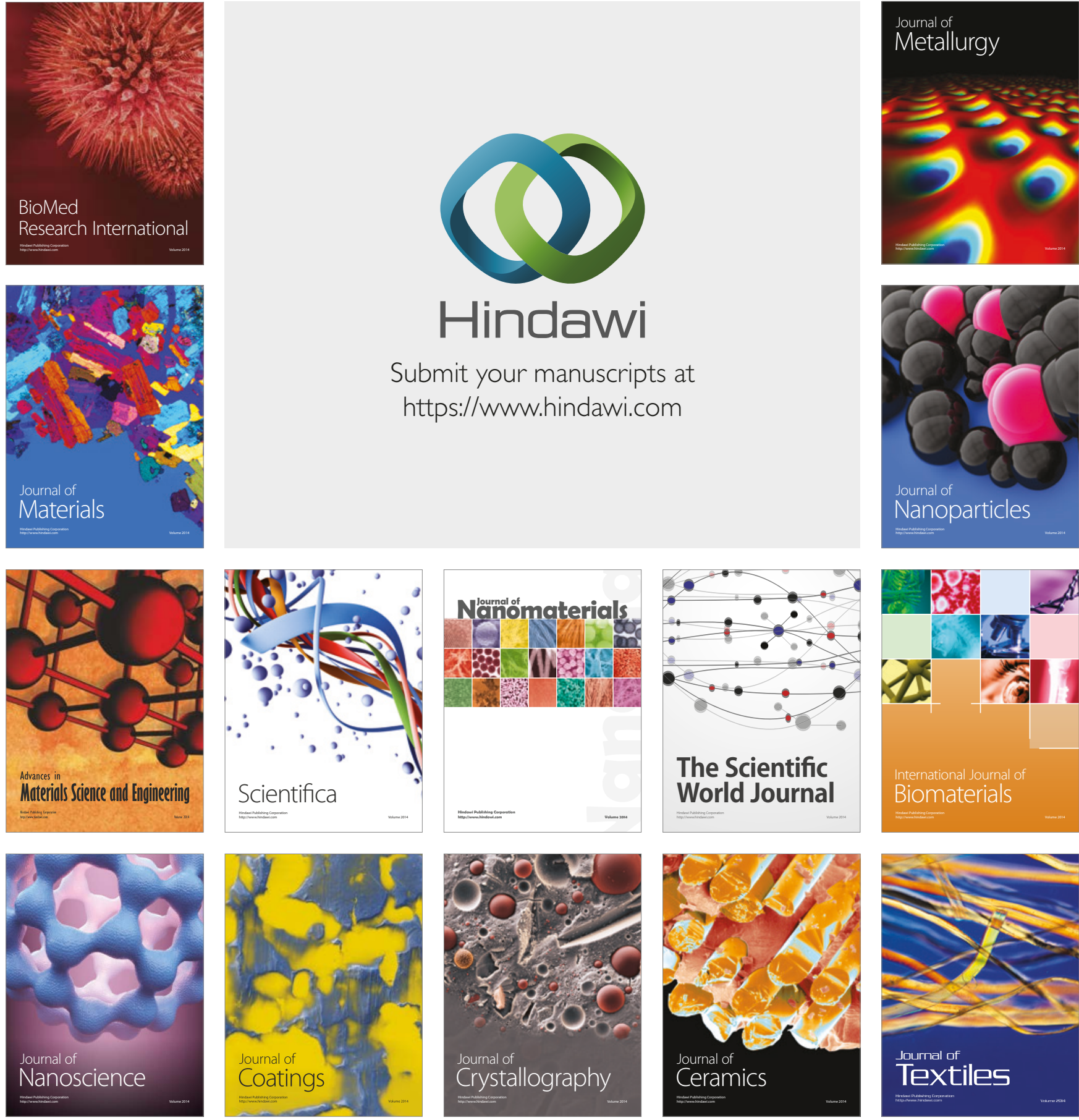

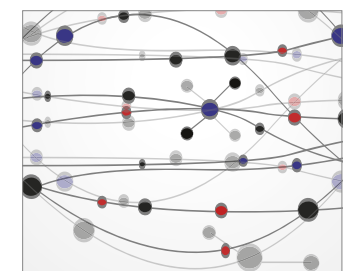

The Scientific World Journal
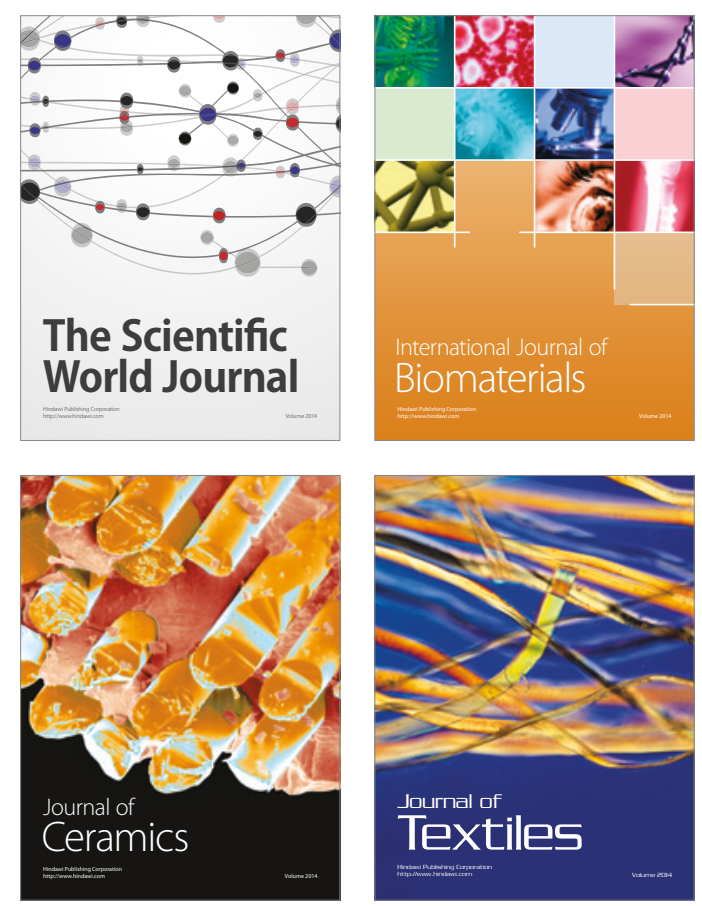